\title{
Biblioteca escolar e a lei 12.244/2010: caminhos para implantação'
}

\author{
School library and the law 12,244, 2010: ways to implementation
}

\begin{abstract}
Cláudio Marcondes de Castro Filho
Doutor em Ciência da Informação pela Escola de Comunicação de Artes da Universidade de São Paulo - USP Docente e Coordenador do Curso de Ciências da Informação e da Documentação da FFCLRP - USP

E-mail: claudiomarcondes@ffclrp.usp.br

Claudinei Coppola Junior Graduado em Ciências da Informação e da Documentação da FFCLRP/USP E-mail: claudineicoppola@hotmail.com
\end{abstract}

\section{Resumo}

Apresenta a situação da biblioteca escolar, nas escolas municipais de ensino fundamental de Ribeirão Preto, tem em vista a Lei $\mathrm{N}^{\circ} 12.244$, de 24 de maio de 2010, que determina a obrigatoriedade das bibliotecas escolares nas instituições de ensino com o bibliotecário, aborda os aspectos básicos da Biblioteca Escolar e da sua importância, bem como o papel do bibliotecário neste contexto. Propõe um modelo às instituições de ensino, destacando os padrões mínimos, para existência da biblioteca, bem como aproximar a comunidade escolar deste novo espaço, integrando-se à escola como parte dinâmica de ações educacionais e culturais.

Palavras-chave: Biblioteca escolar. Bibliotecário. Educação.

\begin{abstract}
Ribeirão Preto Municipal Elementary School System Libraries study in accordance with Law number 12,244 of May 24th, 2010. This Law establishes that school libraries with a Librarian are mandatory, thus addressing the basic aspects and importance of the School Library and, in this context, the role of the School Librarian. We will present a model to guide teaching institutions on the minimum standards for a School Library, as well as to bring the school community closer to this new space as an integral part of the school's educational and cultural activities.
\end{abstract}

Keywords: School Library. Librarian. Education.

\section{Introdução}

O Ensino fundamental é um direito de todas as crianças e adolescentes brasileiros, garantido por lei e aplicado através das secretárias municipais de educação. Nesta fase educacional inicia-se a alfabetização, de acordo com Tfouni (1995, p.15) é entendida como um processo de aquisição individual de habilidades requeridas para a leitura e a escrita, que não se completa nunca, visto que a sociedade está em contínuo processo de mudança, e a atualização individual para acompanhar as mudanças é constante.

\footnotetext{
${ }^{1}$ Agradecimentos ao CNPq pelos subsídios recebidos através do Processo 400722/2010-0
} 
Esforços constantes são necessários, por parte dos professores, para despertar nos alunos a busca do conhecimento. No entanto, a educação pública brasileira necessita de avanços para garantir melhor qualidade de ensino e ampliar o acesso aos livros e a leitura. Apresentaremos neste estudo uma importante aliada: a biblioteca escolar.

Assim como o professor é o personagem central da escola, o bibliotecário também é na biblioteca escolar. Ambos profissionais podem contribuir para alcançar um avanço educacional, conforme declarações da IFLA:

Está comprovado que quando os bibliotecários e os professores trabalham em conjunto, os alunos atingem níveis mais elevados de literacia, de leitura, de aprendizagem; de resolução de problemas e competências no domínio das tecnologias de informação e comunicação. (IFLA, 2000, p.2)

Um fato alarmante que observamos com relação à infraestrutura e ao organograma das escolas públicas é a ausência de bibliotecas escolares e de profissionais habilitados, limitando a formação integral dos alunos, conforme afirma Macedo:

Os pontos críticos, todavia, não recaem tão-somente na inexistência da biblioteca escolar, mas na sua precariedade: ou é "arremedo de biblioteca escolar", sem organização, confusa, e que não pode servir de modelo para o uso correto da informação, ou não conta com alguém motivado para dinamizar a prestação de serviços bibliotecários... (MACEDO, 2005, p.68)

O Censo Escolar, realizado anualmente pelo Instituto Nacional de Estudos e Pesquisas Educacionais Anísio Teixeira (INEP) é o mais relevante e abrangente levantamento estatístico sobre a educação básica no país (BRASIL, 2010a, p.1). No Resumo Técnico - Censo Escolar 2010 é apontado no requisito "Infraestrutura", o número de escolas de ensino fundamental no país que possuem biblioteca (BRASIL, 2010a, p.33), sendo divididos em dois grupos: 1) Escolas dos anos iniciais ( $1^{\circ}$. ao $5^{\circ}$. ano), totalizando 42.029 escolas $(30,4 \%)$; 2$)$ Escolas dos anos finais (6 $6^{\circ}$ ao $9^{\circ}$. ano), totalizando 36.417 escolas (58,7\%). Esse levantamento estatístico é composto por escolas de ensino fundamental, públicas (federal, estadual e municipal) e privadas, no entanto poderá haver divergências no total de "escolas atendidas", pelo conceito incorreto de biblioteca escolar, aplicado pela administração escolar.

Diante das limitações enfrentadas pela biblioteca escolar, uma esperança começa a se desenhar, em 24 de maio de 2010, entrou em vigor a Lei N. 12.244, que dispõe sobre a universalização das bibliotecas nas instituições de ensino no País. O prazo máximo para efetivação da lei será de dez anos, cabendo às instituições "desenvolver esforços progressivos" para o seu cumprimento (BRASIL, 2010b). A partir da aprovação desta lei, 
acentuaram-se as reflexões na Ciência da Informação e Biblioteconomia com relação à biblioteca escolar.

Abordaremos o contexto das escolas municipais de ensino fundamental do município de Ribeirão Preto, do interior do estado de São Paulo, que em sua maioria não possuem biblioteca escolar e tentaremos propor um modelo com padrões mínimos para implantação de bibliotecas escolares com a atuação de bibliotecários, para a aplicação da Lei 12.244/2011.

\section{Metodologia}

A pesquisa foi elaborada em dois períodos: levantamento bibliográfico e análise documental. A pesquisa bibliográfica sobre o tema biblioteca escolar foi realizada em: publicações de teóricos das áreas de Biblioteconomia e Ciências da Informação; análise de documentos de Instituições Internacionais tais como: "Diretrizes da IFLA/UNESCO para Bibliotecas escolares", "Manifesto IFLA/UNESCO para Biblioteca Escolar" e "Declaração Política da IASL sobre Bibliotecas Escolares”, que buscou relacionar a problemática das escolas de ensino fundamental com os conceitos e soluções propostas pelos teóricos e instituições internacionais direcionados a biblioteca escolar, em seguida, elaboramos um modelo básico para implantação de bibliotecas escolares.

\section{A cidade de Ribeirão Preto}

Nascida em 1856, em uma clareira onde, um século antes os Bandeirantes estiveram de passagem, a cidade ganhou impulso com a lavoura de café, cultivada pelos imigrantes e fertilizada pela terra vermelha - "rossa" para os italianos e "roxa" no linguajar caboclo. A terra de Ribeirão Preto transformou a região no maior produtor de grãos na virada do século XIX. Abastecia o mundo inteiro com o que se chamava "ouro verde". A antiga clareira, banhada por dois córregos, logo se transformou em uma importante cidade, ligada ao país por ferrovia, telefonia e rodovias. O desenvolvimento trouxe novas culturas, como a cana-de-açúcar, a soja, o milho, o algodão, a laranja e implantou uma forte agroindústria (RIBEIRÃO PRETO, 2011).

Ribeirão Preto situa-se no Nordeste do estado de São Paulo a $313 \mathrm{~km}$ da capital. Segundo o Censo Demográfico de 2010, possui 605.114 habitantes, o município de Ribeirão Preto se encontra entre os maiores do Estado de São Paulo e do Brasil (IBGE, 2011). 


\section{Histórico da Educação em Ribeirão Preto: ensino fundamental}

No que se refere ao início do ensino primário em Ribeirão Preto, Cione (1997) informa que previamente a instalação de escolas municipais e estaduais foram criadas escolas particulares, para o ensino das primeiras letras, que passaram a ser reguladas pela Câmara Municipal em 1874.

O ensino municipal propriamente dito, regulamentado pela Lei n. 104, de 1904, iniciou-se com a criação e a instalação de uma escola localizada na Fazenda Santa Amélia. Surgiram outras escolas posteriormente, sendo instituída a obrigatoriedade do ensino primário através da Lei n. 240, de 1920 (CIONE, 1997). Quanto aos Grupos Escolares, Cione (1997) informa a criação de cinco denominados: "Dr. Guimarães Junior” (inaugurado em 1902), "Fábio Barreto", "Sinha Junqueira, “Antônio Diederichsen” e "Conego Barros”.

Diversas outras iniciativas (voltadas para todos os níveis) de instituições de ensino, públicas ou privadas, surgiram em Ribeirão Preto, contemplando diversas universidades, entre elas a Universidade de São Paulo, atraindo estudantes da região de Ribeirão Preto e de outras partes do país. No entanto, nos limitaremos a este breve histórico educacional para retornarmos ao ensino fundamental.

A partir de 2010, o Ensino Fundamental passou a ter duração mínima de 9 anos, de acordo com a Lei N. 11.274, de 6 de fevereiro de 2006, que estabelece as diretrizes e bases da educação nacional, dispondo sobre a duração de 9 (nove) anos para o ensino fundamental, com matrícula obrigatória a partir dos 6 (seis) anos de idade (BRASIL, 2006).

O Conselho Municipal de Educação, visando melhorias no ensino aprovou o Plano de Municipal de Educação de Ribeirão Preto. Sobre o Ensino Fundamental, o plano abordava nos "Objetivos e Propostas", a necessidade da implantação de bibliotecas com bibliotecários:

13. Implantar um planejamento arquitetônico e administrativo, para as escolas, com a participação da comunidade escolar, de modo a garantir unidades funcionais, incluindo:

[...] c) espaços e recursos materiais para esporte, arte, recreação, biblioteca (com profissional especializado), brinquedoteca [...].(RIBEIRÃO PRETO, 2008, p.33, grifo nosso) 
As escolas municipais de ensino fundamental de Ribeirão Preto totalizam 28 (vinte e oito) unidades escolares ${ }^{2}$, que em sua maioria não possuem biblioteca escolar. Através deste estudo, buscaremos esclarecer os principais aspectos e a importância deste ambiente de informação na educação brasileira.

\section{A Biblioteca Escolar}

Quais sejam os princípios que pensarmos para a escola que queremos, o aparelho funcional da estrutura da escola de $1^{\circ}$ grau pressupõe, hoje, uma biblioteca escolar (GARCIA, 1989).

Biblioteca escolar é definida por Corrêa et al. (2002) como uma instituição onde estão organizados itens bibliográficos, como também outros meios, onde estão disponibilizadas as informações, de maneira que satisfaça seus usuários, despertando-os para a pesquisa e leitura, desenvolvendo sua criatividade e sua consciência crítica.

Para Castro Filho e Romão (2011), a biblioteca escolar "é um espaço de confluência, imbricação, encontro e diálogo de várias vozes, manifestas em livros, revistas, jornais, quadrinhos, filmes, etc.; é ainda local de aprendizagem, leitura e fomento cultural".

O manifesto IFLA/UNESCO para biblioteca escolar apresenta a missão das bibliotecas:

A biblioteca escolar (BE) propicia informação e ideias fundamentais para seu funcionamento bem sucedido na atual sociedade, baseada na informação e no conhecimento. A BE habilita os estudantes para a aprendizagem ao longo da vida e desenvolve a imaginação, preparando-os para viver como cidadãos responsáveis. (IFLA, 2000, p.1)

A missão das bibliotecas escolares é definida por Côrte e Bandeira na afirmação a seguir:

\footnotetext{
A biblioteca escolar é um espaço de estudo e construção do conhecimento, coopera com a dinâmica da escola, desperta o interesse intelectual, favorece o enriquecimento cultural e incentiva a formação do hábito da leitura. (CÔRTE; BANDEIRA, 2011, p.8)
}

A biblioteca escolar estará inserida em uma instituição de ensino, com a finalidade essencial de atender as necessidades da comunidade escolar. Para cumprir sua missão é

2 RIBEIRÃO PRETO. Conhecendo a rede municipal de ensino. Disponível em:

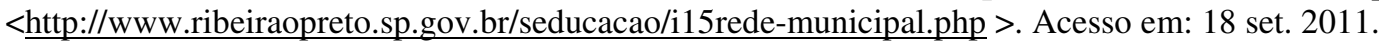


necessário ser planejada, com o envolvimento de toda a sua comunidade, de forma a oferecer serviços informacionais imprescindíveis ao ambiente escolar.

No entanto, a biblioteca escolar apresenta uma difícil realidade, principalmente na rede pública de ensino, de acordo com Corrêa et al.:

Além das já conhecidas precariedades em termos de espaço físico e acervo, muitas delas 'funcionam' com a presença de profissionais de diversas áreas, principalmente da educação, como professores e funcionários de diversos departamentos da escola, geralmente readaptados e aguardando a aposentadoria.(Corrêa et al., 2002, p.108)

Nas escolas municipais de ensino fundamental de Ribeirão Preto, a situação não é diferente, as unidades escolares possuem salas de leitura, contendo livros em estantes, porém sem organização adequada, contando com pessoal não especializado. Confirmando essa situação, o Prof. Dr. César Augusto Minto, da Faculdade de Educação da USP, elaborou uma análise do Plano Municipal de Educação de Ribeirão Preto, aprovado na I Conferência Municipal de Educação, abordando a situação das bibliotecas no Ensino Fundamental:

Ensino Fundamental (EF)

Principais problemas: [...] 6) Situação precária de bibliotecas e laboratório de ciências e pequena presença de salas para TV/Video; [...] 7) Laboratórios e bibliotecas não estão presentes em todas as escolas e, quando existem, são mantidos em condições que comprometem o seu uso adequado. (MINTO, 2008, p.6-7, grifo nosso)

A existência de Bibliotecas Escolares está diretamente relacionada com a presença de profissional qualificado: o bibliotecário.

\subsection{Bibliotecário Escolar}

No Brasil, o exercício da profissão de bibliotecário é disciplinada pelas Leis: 4.084, de 30 de junho de 1962, e 9.674, de 25 de junho de 1998, que exige a formação de nível superior através do Bacharelado em Biblioteconomia.

De acordo com o Manifesto IFLA/UNESCO para Biblioteca Escolar (2000), esse profissional é apresentado como: “O bibliotecário escolar é o membro profissionalmente qualificado, responsável pelo planejamento e gestão da biblioteca escolar. Deve ser apoiado tanto quanto possível por equipe adequada, trabalha em conjunto com todos os membros da comunidade escolar e deve estar em sintonia com bibliotecas públicas e outros". 
Para Caldin (2005, p.167), a essência do papel do bibliotecário é fazer da biblioteca escolar um centro promotor de leitura. Para atingir esse objetivo é extremamente necessário que goste de ler, sendo um bom exemplo para a comunidade escolar.

De acordo com Ferrarezi e Castro Filho (2011, p. 116), "a ação do bibliotecário é focar nos leitores e não apenas no acervo", e ainda, na realização de "ações culturais e de utilização de tecnologias para organizar, processar e disseminar informações, como também promover a chamada competência informacional”. Nesse sentido, Campello (2011) ainda completa a ação do bibliotecário, como colaborador na pesquisa escolar, ou seja, a inserção do bibliotecário, no processo do letramento informacional na biblioteca escolar.

Segundo Ely (2003, p. 47), o bibliotecário precisa cativar os neoleitores, sendo necessário possuir algumas características: “Atuar na biblioteca escolar exige ótima saúde, muita paciência, entusiasmo, perspicácia, espírito crítico, bom humor, afetividade, alegria, simpatia, entre muitas outras qualidades".

O bibliotecário escolar, de acordo com Corrêa et al. tem como funções: tarefas administrativas, tarefas educacionais e tarefas técnicas. Aborda também sobre a interação do bibliotecário com a comunidade escolar:

O bibliotecário precisa participar ativamente de todos os acontecimentos que circundam o ambiente escolar, bem como ter conhecimento da política educacional da instituição na qual atua, estando atento a todos os aspectos que envolvem seu trabalho no contexto escolar, interagindo também através da parte técnica necessária ao bom funcionamento da biblioteca. (CORRÊA et al., 2002, p. 116-8)

O bibliotecário que conseguir aproximar os alunos da biblioteca e da informação, bem como conquistar a confiança dos professores e da direção pedagógica, divulgando as potencialidades de sua unidade de informação perante a comunidade escolar, atingirá os objetivos institucionais e sociais da biblioteca escolar.

A Rede municipal de ensino de Ribeirão Preto não possui nenhum profissional bibliotecário atuando na Secretaria Municipal de Educação. Segundo Minto, em sua análise do Plano Municipal de Educação de Ribeirão Preto, aprovado na I Conferência Municipal de Educação, apresenta uma crítica ao Plano por não preverem a contratação de bibliotecários no quadro de funcionários das escolas municipais, citando nos "Objetivos e Propostas" para formação e valorização de profissionais da educação, no seguinte comentário: 
O item 14 prevê um prazo de dois anos para elaboração e implementação do módulo de funcionários nas escolas municipais (aqui cabe um reparo, pois não se previu profissionais para bibliotecas e laboratórios, a não ser que estejam contemplados no “etc.”). (MINTO, 2008, p.14-5, grifo nosso)

Excelentes iniciativas públicas como o Plano Municipal de Educação de Ribeirão Preto, silenciam o papel do bibliotecário em suas propostas devido ao desconhecimento das habilidades deste profissional pela comunidade escolar. Segundo Kieser e Fachin (2000, p. 10), os bibliotecários devem exigir os seus espaços junto à biblioteca escolar, promovendo o reconhecimento das suas funções assim como os demais setores das unidades escolares são considerados, completando o quadro profissional das escolas de ensino fundamental.

Apresentadas as características do ensino fundamental, da biblioteca escolar, do bibliotecário, sugerimos um modelo de biblioteca escolar, de forma a explorar o seu potencial na melhoria da educação das escolas municipais de Ribeirão Preto.

\subsection{Modelo de Biblioteca Escolar}

Segundo Diretrizes da IFLA/UNESCO (2006, p.11) a qualidade dos recursos da biblioteca dependem dos recursos humanos existentes, com número suficiente a depender da dimensão da escola, sendo composta por bibliotecário e auxiliar de biblioteca.

A Infraestrutura da biblioteca escolar, segundo Diretrizes da IFLA/UNESCO (2006, p.7) e da Declaração Política da IASL (1993) deverá atender os seguintes requisitos:

a) Os espaços deverão, localizar-se próximo dos locais de maior circulação e serem de fácil acesso a todos usuários;

b) Iluminação adequada e suficiente, por meio de fonte natural e artificial;

c) Temperatura e umidade ambiente apropriada (ar condicionado) e monitorização (termohigrômetro), garantindo a preservação das coleções;

d) Tratamento acústico das portas e piso;

e) Dimensão adequada, possibilitando espaço para: coleção de livros, mídias e outros formatos, zonas de balcão de atendimento, zonas de estudo e leitura, zonas de produção e trabalho em grupo.

A biblioteca escolar, conforme as Diretrizes da IFLA/UNESCO (2006, p.6), deverá possuir verbas previstas no orçamento escolar, a fim de viabilizar: novos recursos (acervo); 
materiais de promoção; materiais de consumo e administrativo; custo e utilização de Tecnologias de Informação e Comunicação (TIC).

O mobiliário necessário à biblioteca escolar, conforme descrevem Côrte e Bandeira (2011, p.25-9) é composto de: estantes, mesas, cadeiras, escadas, balcão de empréstimo, bibliocantos ou suporte de livros, carros de transporte de material bibliográfico, fichários, arquivos verticais, expositores para livros, revistas e vídeos, quadro de avisos, armário, guarda-volumes, poltronas, guias de prateleiras, guias de estantes, mapotecas e porta jornais.

Os equipamentos eletrônicos necessários para a biblioteca escolar, segundo Nascimento e Castro Filho (2007) seriam: televisor, vídeo cassete, aparelho DVD, rádio, computadores com acesso a internet, copiadora, scanner e câmeras.

A sinalização em biblioteca tem por objetivo, segundo Hauenstein, Santini e Kuse (1999): "a orientação dos usuários quanto aos serviços que a biblioteca oferece, facilitando seu acesso, seu uso e dinamizando seu funcionamento". Permite identificar e localizar a biblioteca; identificar áreas de serviços, acomodações; informar regulamentos, horários e fatos especiais.

A composição do acervo, de acordo com Nascimento e Castro Filho (2007, p. 10), deverá ser constituída de: livros, obras de referência, periódicos, audiovisuais, material didáticos, materiais de animação cultural. Deverá ser elaborada pelo bibliotecário uma política de seleção e aquisição de coleções. Segundo Ely (2003, p.47), a organização e tratamento da informação serão elaborados pelo bibliotecário escolar, a partir das normas biblioteconômicas.

Para Corrêa et al. (2002, p. 112), os principais objetivos e serviços da biblioteca escolar visam: cooperar com o currículo escolar; proporcionar aos usuários, materiais diversos e serviços informacionais adequados; orientar e estimular os alunos em todos os aspectos da leitura. O horário de funcionamento deve ser adequado e flexível aos usuários.

O bibliotecário escolar e a comunidade escolar devem estabelecer, conforme as Diretrizes da IFLA/UNESCO (2006, p.3), políticas estruturadas com clareza, destacando a filosofia, o conceito e as intenções da biblioteca escolar.

A implantação das bibliotecas escolares será possível através de um planejamento que deve envolver diversas esferas do governo municipal, entre elas: Secretaria de Educação, Secretaria de Obras Públicas, Conselho Municipal de Educação e Gabinete da Prefeitura 
Municipal. O processo de implantação poderá ser facilitado através de uma parceria junto a Universidade de São Paulo, do campus Ribeirão Preto, através do corpo docente e discente do curso Ciências da Informação e Documentação da Faculdade de Filosofia, Ciências e Letras de Ribeirão Preto.

\section{Considerações finais}

A Educação pública brasileira necessita de inúmeras melhorias para a qualidade da educação. A Lei N. ${ }^{\circ}$ 12.244/2010 representa um dos maiores avanços, no sentido do Estado se posicionar frente ao Manifesto da IFLA/UNESCO para biblioteca escolar. Porém, cabe à comunidade escolar, aos professores, aos bibliotecários, reivindicar a aplicação desta lei, de forma a impedir que seja esquecida e suprimida por outros interesses.

A implantação de bibliotecas escolares, nas escolas municipais de Ribeirão Preto, será possível se ocorrer o reconhecimento da importância da biblioteca escolar por parte da Secretaria Municipal de Educação. Em seguida serão necessárias algumas adequações na infraestrutura das escolas e no quadro de servidores da Secretaria de Educação com a contratação de bibliotecários, envolvendo a comunidade escolar de cada unidade de ensino.

Legislação específica, diretrizes e padrões já representam uma realidade para a implantação das bibliotecas escolares, no entanto, o agir dos responsáveis pela educação municipal e o envolvimento da comunidade escolar consolidará essa conquista na rede municipal de ensino de Ribeirão Preto, possibilitando a milhares de crianças e adolescentes o acesso à informação, cultura e cidadania.

\section{Referências}

BRASIL. Lei n. ${ }^{\circ}$ 11.274: Estabelece as diretrizes e bases da educação nacional, dispondo sobre a duração de 9 (nove) anos para o ensino fundamental, com matrícula obrigatória a partir dos 6 (seis) anos de idade. Brasília: Congresso Nacional, 2006.

BRASIL. Ministério da Educação. Resumo Técnico - Censo Escolar 2010. Brasília: INEP, 2010a. Disponível em:

$<$ http://portal.mec.gov.br/index.php?option=com_content $\& v i e w=$ article $\& i d=16179>$. Acesso em: 19 mar. 2011. 
BRASIL. Lei n. ${ }^{0}$ 12.244: Dispõe sobre a universalização das bibliotecas nas instituições de ensino do País. Brasília: Congresso Nacional, 2010b.

CALDIN, Clarice Fortkamp. Reflexões acerca do papel do bibliotecário de biblioteca escolar. Rev. ACB: Biblioteconomia em Santa Catarina, Florianópolis, v. 10, n. 2, p. 163-168, 2005.

CAMPELLO, Bernadete. Práticas de letramento informacional em bibliotecas escolares brasileiras: colaboração do bibliotecário com os professores. In: CASTRO FILHO, Claudio Marcondes de; ROMÃO, Lucília Maria Sousa. Dizeres sobre biblioteca escolar: palavras em movimento. Ribeirão Preto: Alphabeto, 2011.

CASTRO FILHO, Claudio Marcondes de; ROMÃO, Lucília Maria Sousa. Livros-Ninhos e Leitores-Passarinhos: outros sentidos de documento. In: CRIPPA, Giulia; MOSTAFA, Solange Puntel. Ciência da Informação e Documentação. Campinas: Alínea, 2011.

CORTE, Adelaide Ramos e; BANDEIRA, Suelena Pinto. Biblioteca Escolar. Brasília: Briquet de Lemos, 2011.

CIONE, Rubem. História de Ribeirão Preto. Ribeirão Preto: Imag, v. 5, 1997.

CORRÊA, Elisa Cristina Delfini; et al . Bibliotecário escolar: um educador?. Rev. ACB: Biblioteconomia em Santa Catarina, Florianópolis, v. 7, n. 1, 2002, p. 107-123.

ELY, Neiva Helena. Dimensões da biblioteca escolar no ensino fundamental. Rev. ACB: Biblioteconomia em Santa Catarina, Florianópolis, v. 8/9, p. 46, 2003/2004.

FERRAREZI, Ludmila; CASTRO FILHO, Claudio Marcondes de. Atuação profissional na biblioteca escolar: outras perspectivas. In: CASTRO FILHO, Claudio Marcondes de; ROMÃO, Lucília Maria Sousa. Dizeres sobre biblioteca escolar: palavras em movimento. Ribeirão Preto: Alphabeto, 2011.

GARCIA, Edson Gabriel. Biblioteca escolar: estrutura e funcionamento. São Paulo: Loyola, 1989.

HAUENSTEIN, Deisi Maria; SANTINI, Luciane; KUSE, Mara. Sinalização. [1999]. Disponível em: <http://campus.fortunecity.com/mcat/102/sinaliza.htm>. Acesso em: 26 mar. 2011.

INTERNATIONAL ASSOCIATION OF SCHOOL LIBRARIANSHIP. Declaração política da IASL sobre bibliotecas escolares, 1993.

IBGE - INSTITUTO BRASILEIRO DE GEOGRAFIA E ESTATÍSTICA. Censo demográfico de Ribeirão Preto 2010. Disponível em: <http://www.ibge.gov.br/cidadesat/topwindow.htm?1> Acesso em: 18 mar. 2011.

IFLA - INTERNATIONAL FEDERATION LIBRARY ASSOCIATIONS AND INSTITUTIONS. Diretrizes da IFLA/UNESCO para bibliotecas escolares. Tradução de Maria José Vitorino. IFLA, 2006.

Manifesto IFLA/UNESCO para biblioteca escolar. Tradução Neusa Dias Macedo. São Paulo: IFLA, 2000. 
KIESER, Herta; FACHIN, Gleisy Regina Bóries. Biblioteca escolar: espaço de interação entre bibliotecário-professor-aluno-informação - um relato. Florianópolis: UFSC, 2000.

MACEDO, Neusa Dias. Biblioteca escolar brasileira em debate: da memória profissional a um fórum virtual. São Paulo: Senac São Paulo, Conselho Regional de Biblioteconomia - $8^{\mathrm{a}}$. Região, 2005.

MINTO, César Augusto. Plano Municipal de Educação de Ribeirão Preto uma construção coletiva: Análise do documento aprovado na I Conferência Municipal de Educação em 28/5. São Paulo, 2008. Disponível em: <

http://www.ribeiraopreto.sp.gov.br/seducacao/conselho/pmeduca/analise.php $>$. Acesso em: 18 mar. 2011.

NASCIMENTO, Aline Mendes do; CASTRO FILHO, Cláudio Marcondes de. Retrato das bibliotecas escolares da rede estadual de ensino do município de Ribeirão Preto-SP.

Biblionlinle, João Pessoa, v. 3, n. 1, 2007.

RIBEIRÃO PRETO. Conselho Municipal de Educação. Plano Municipal de Educação de Ribeirão Preto: Uma construção coletiva. I Conferência Municipal de Educação, 2008.

Conhecendo a rede municipal de ensino. Disponível em:

$<$ http://www.ribeiraopreto.sp.gov.br/seducacao/i15rede-municipal.php $>$. Acesso em: 06 Nov. 2010 .

Histórico de Ribeirão Preto. Disponível em:

<http://www.ribeiraopreto.sp.gov.br/crp/i71historico.htm>. Acesso em: 19 Mar. 2011.

TFOUNI, Leda Verdiani. Letramento e alfabetização. São Paulo: Cortez, 1995. 